Mr. Spencer distinctly refuses to identify this principle with the great physical principle of the Conservation or the Persistence of Energy, the firm establishment of which undoubtedly marks one of the most important epochs in the history of Science. Force, in Mr. Spencer's use of the term, includes numerous species of which energy is but one. I feel sure that every mathematician and physicist would protest against the inclusion uncler one term of magnitudes of such different kinds as statical force and energy, or the work done by such a force; but not to dwell on this, believe that $\mathrm{Mr}$. Spencer would certainly acknowledge as one of his species, that which (in my view) is alone properly termed Force, namely, such as can be measured in terms of the weight of a pound or a gramme. What then does Persistence of Force of this kind mean? Does it mean that the numerical sum of the intensities of all the Actions and Reactions throughout the universe is constant? If so, it is untrue: for, to take a simple illustration, if a weight be supported, first by a single string, and then by two strings not vertical, the tensions are quite difierent in the two cases, and there is no equivalence between those which disappear, and those which are introduced in passing from one to the other. If not, we must take account of the directions of our forces, and then, if it mean anything, it appears to be but the expression of Newton's Third Law that " action and reac ion are equal and contrary" in this form:- "The algebraieal sum of all the forces throughout the universe is persistently zero." To cvery mathematician, at any rate, this assertion and the assertion that "the sum of the energies of all kinds throughout the universe remains persistently of the same definite numerical amount" are assertions of facts of such different orders, that to class them together is rather to introduce confusion of thought than to establish a grand general principle.

I have offered the above remarks because it appears to me only fair to the author of the article on Herbert Spencer in the British Quarterly Reviezu to show that it is felt by others, who have made a study of the fundamental principles of rational mechanics, that his strictures on Mr. Spencer's treatment of those principles are in all essential points fully justified, however much they may wish that the expression of those strictures had been in some instances modified in its tone.

The Park, Harrow, April 20 ROBErT B. Hayward

I THINk it is positively due, not only to the writer of the now famous article in the British Quarterly Review, but to Newton's memory and to Science itself, that the correspondence which has been going on should not seem to terminate as a drawn game, at any rate in the opinion of some bystanders, who may from their antecedents be presumed competent to judge.

That Mr. Spencer will ever be convinced is, I suppose, hopeless ; I at any rate am not going to try to convince him. But I can assure the British Quarterly Reviewer that he has my very deepest sympathy in his argument with an antagonist who is at once so able a ma ter of fence as Mr. Spencer, and yet is so intensely unmathematical, it would seem, as to pass from "exact quantitative relation " to "proportionality ;" or as to talk of the effect of a force, without defining how the effect is to be measured, without feeling the slightest difficulty.

Nor does it seem that Mr. Frankland, in NATURE, vol. ix., p. 484 , is quite justified in his conclusion that the truth lies betzueen the two opposite views. And his own view is in fact entirely coincident with the Reviewer's, except, perhaps, on a point which is not relevant to the controversy, viz. how far the cxperimental proof of the so-called physical axioms is complete.

IVill it comfort the Reviewer if I tell him some of my own experience? I, too, read Spencer after my degree; and on the first reading of the "First Principles" came to the sad conclusion that I had not understood any mathematics properly ; so much fresh light seemed to be thrown on them. I read it again, and more critically, and doubted whether Spencer was quite correct. I read it again, and concluded that he was wrong in his physics and mathematics. I ought to add that I too was, like the Reviewer, A SENior Wrangler

I AGREE so fully with thine chief contents of Mr. Frankland's letter (vol. ix. p. 484), that I wish to call his attention to one point in which his letter seems to me calculated to mislead.

He says, "the pure empiricists argue that because certain observed results coincide with the resuits of calculation, therefore the assumptions on which the calculation was based must be true. Now without doubt the demonstrative character of this inference vanishes entirely under Mr. Spencer's searching
criticism. But it seems to me that a hizh probability remains."

Now, in the name of pure empiricists, I must protest against our being supposed to think that anything "must be true" in any other sense than that there is a "high probability" of its truth. I cannot refer to a better exponent of our views on this point than Prof. Clifford, to whom Mr. Frankland himself refers. And the idea of our having to thank Mr. Spencer for showing that the inductive proofs of the laws of motion (or of any other physical truths) are not demonstrative in any other sense than the above is quite new to us. What Mr. Spencer has done is to bring up instances of this so-called imperfectness in the demonstration as evidences that no i posteriori proof of the proposition can exist, when in point of fact they are specially characteristic of such a proof.

Those of your readers who have examined Mr. Spencer's ingenious proof of the second law of motion, contained in his last letter to NATURE (vol. ix. p. 46r), will not ascribe my not imme. diately answering his letter to any difficulty in so doing.

The Author OF THE ARTICLE IN THE BRITISH QUARTERLY REVIEW

\section{Lakes with two Outfalls}

In NatuRr, vol. ix., p. 485, Mr. Craig Christie begins a letter " to correct a mistake as to a matter of fact :" "Loch-naDavie, Arran, has two outlets, as is correctly represented in the Ordnance map;" and he ends his letter: "I think Colonel Green. wood ought at least to have made himself acquainted with the Ordnance map."

I take the liberty to enclose to you the new Inch Ordnance map of Arran, to which my letter in vol. ix. p. 4tI referred. You will see that as "a matter of fact" the map does not give two outlets, but only one.

I need not ask for your valuable space in reference to Mr. Christie's own "matters of fact," since my views with reference to them are printed in the Athenaum of July 22, 1865. He will see there that I have not only "walked up the north stream from Loch Ranza," but also by Glen Catacol and Glen Dzeven, and a third time from Corrie by Glen Sannox over the waterparting. Also that I have sounded the whole of this littie pool of bog-water by walking it, bare-legged, without being over my knees in the deepest part, which was at the south end, where the only outlet is to Gfen Iorsa.

I shall have the pleasure to communicate with Mr. Thelwall in reference to his obliging letter.

[The Ordnance map forwarded to us by Colonel Greenwood gives only one outlet to Loch-na-Davie.-ED.]

As this subject appears to me to possess an interest apart from the issues hitherto in question, I trust you will allow me a little of your space.

From the fact that lakes do not ordinarily occupy the crest of a watershed, it would $\dot{a}$ priori appear more likely that a double outfall, if it exist, should lie in or towards adjacent districts than connected with opposed valley systems. The following in. stance, which I observed in Norway last summer, is, in view of Colonel Greenwood's letter (NATURE, vol. ix. p. 44I), worth mentioning. The lake exhibiting it lies about two miles inland (N.W.) from the elevated coast which faces Trondhjem, and is named Stor Lake; its length-nearly parallel to the Trondhjem fjord-is about seven miles, its greatest breadth about two. Like many Norwegian lakes, it presents a facies different to what we are most familiar with in Britain. Instead of occupying a single valley-basin, it consists of a chain of minor basins strung along an axis of depression (probably a pre-existing valley), and each separated from its neighbours by the subsided walls of the valley of which it is the cup-like enlargement. The form of Stor Lake is irregular, with long arms or creeks extended (obliquely to its longer axis) into the mouths of the valleys. In such lakes it might be expected now and then that the effluent waters should pass out at more than one of these channels, and in Stor Lake such is the case. One stream is discharged from one of the component basins, nearly at right angles to the lake's greatest length, the other issues along the depression on which I have said the basins are "strung"-bead-like. The former opening is of post-glacial date, and is superseding the original one for several reasons :- (I) it flows along the strike of a homogeneous bed of schist, whereas the other cuts across beds of various textures, and (2) its volume is greater. Its rival bears evident traces of 